


\title{
Complementaridades institucionais para o financiamento do investimento no Brasil: análise da relação de entre FAT e BNDES
}

\section{Institutional complementities for investment financing in Brazil: Analysis of the relationship between FAT and BNDES}

\author{
Sandro Pereira Silva* \\ http://dx.doi.org/10.51861/ded.dmvu.2.005 \\ Recebido em 7 de dezembro de 2020. Aceito em 17 de março de 2021.
}

\begin{abstract}
Resumo
Este texto tem como tema a construção de capacidades estatais para o investimento de médio e longo prazo. $O$ foco recaiu sobre a relação entre fundos públicos e agentes financeiros estatais na formação de arranjos institucionais para o financiamento do desenvolvimento econômico, a partir de uma estratégia específica. Buscou-se analisar os mecanismos pelos quais o Fundo de Amparo ao Trabalhador (FAT) absorve e disponibiliza recursos para projetos de interesse nacional, gerenciados pelo Banco Nacional do Desenvolvimento Econômico e Social (BNDES). Observou-se que existe uma complexa relação de complementaridade institucional envolvendo o FAT e o BNDES, cuja trajetória foi marcada por forte instabilidade nos últimos anos, o que se configura em uma situação preocupante em termos de planejamento econômico pelo fato do FAT ser um dos principais geradores de funding para o BNDES, que por sua vez, é o principal agente financiador de médio e longo prazo no país.
\end{abstract}

Palavras chave: Fundo de Amparo ao Trabalhador; BNDES; Capacidade de investimento; Capacidades estatais; Complementaridade institucional.

\begin{abstract}
The theme of this text is the construction of state capacities to enable medium and long term investment. The focus was on the relationship between public funds and state financial agents in the formation of institutional arrangements for the financing of economic development, based on a specific strategy. We sought to analyze the mechanisms by which the Worker Support Fund (FAT) absorbs and makes available resources for projects of national interest, managed by the National Bank for Economic and Social Development (BNDES). It was observed that there is a complex relationship of institutional complementarity involving FAT and BNDES, whose trajectory was marked by strong instability in recent years, which is a worrying situation in terms of economic planning because FAT is one of the main generators of funding for the BNDES, which in turn is the main medium and long-term financing agent in the country.
\end{abstract}

Keywords: Worker Support Fund; BNDES; Investment capacity; State capacities; Institutional complementarity.

\footnotetext{
* Sandro Pereira Silva

Técnico de Planejamento e Pesquisa no Instituto de Pesquisa Econômica Aplica (IPEA). Av. Pres. Vargas, 730 Centro, Rio de Janeiro.

ORCID: 0000-0002-8836-0128. E-mail: sandro.pereira@ipea.gov.br
} 


\section{INTRODUÇÃO}

A relação positiva entre investimento em infraestrutura e crescimento econômico é bem documentado na literatura macroeconômica (DEMETRIADES \& MAMUNEAS, 2000; ESFAHANI \& RAMIREZ, 2003; CALDERÓN \& SERVEN, 2004), assim como o impacto sobre a distribuição de renda e a diminuição da pobreza (ESTACHE, FOSTER \& WODON, 2002; CALDERÓN \& CHONG, 2004; GOMES, PEREIRA \& BEZERRA, 2019). No entanto, a manutenção de níveis desejados de investimento agregado consiste em um dos desafios fundamentais na condução de política econômica, sobretudo em contextos de falhas de mercado de crédito, que provoca restriçốes na disponibilidade de financiamentos para projetos de interesse nacional que exigem longa maturação.

Para enfrentar questôes como essa, os Estados nacionais desenvolvem ao longo do tempo distintas estratégias, como a criação de intermediários financeiros com institucionalidade específica, os chamados bancos públicos de desenvolvimento (BPD), que buscam viabilizar instrumentos adequados para o financiamento de longo prazo em moeda local. Entre as razões que justificam este tipo de atuação estão: $i$ ) compensar a escassez de crédito para impulsionar setores intensivos em capital; ii) financiar projetos de alto retorno social, mas que exigem longa maturação ou apresentam baixo retorno financeiro; e iii) prospectar oportunidades de investimentos reconhecidas ou a serem exploradas pelo setor privado. Tais fatores permitem considerar os BPD como instrumentos fundamentais para a promoção de uma estratégia desenvolvimentista de ação estatal, conhecida na literatura como Estado Desenvolvimentista, visando a ativação e fortalecimento do circuito produtivo nacional (AMSDEN, 2001; CHANG, 1999; ROUTLEY, 2012; WADE, 1990).

Por sua vez, os questionamentos mais comuns à atuação desses agentes apontam que o baixo custo de seu capital, por advir majoritariamente de poupança compulsória, não reflete o seu real custo de oportunidade, além impactar na estrutura da dívida pública pelo custo fiscal implícito no diferencial de juros. Ademais, a mobilização de fundos para essa finalidade envolve uma complexidade de fatores provenientes das decisões de investimento, no tocante às incertezas quanto a risco e retorno esperado (CRUZ, 1994; CINTRA \& PRATES, 2010; ARAÚJO \& CINTRA, 2011; ALÉM, MADEIRA \& MARTINI, 2015; MUSACCHIO \& LAZZARINI, 2015).

Para este trabalho, o tema central refere-se à construção de capacidades estatais ${ }^{1}$ para a viabilização do investimento de médio e longo prazo na economia brasileira, com estabilidade em suas bases de financiamento e autonomia em relação ao mercado interno de capitais. $\mathrm{O}$ foco recaiu sobre a relação de 
complementaridade institucional ${ }^{2}$ entre fundos públicos e bancos de desenvolvimento a partir de uma estratégia específica e operacionalmente complexa. Buscou-se analisar os mecanismos pelos quais o Fundo de Amparo ao Trabalhador (FAT) obtém e disponibiliza recursos para projetos de interesse nacional, gerenciados pelo principal agente de financiamento dessa natureza no Brasil, o Banco Nacional do Desenvolvimento Econômico e Social (BNDES).

Partiu-se de uma construção analítica histórico-institucional, acompanhada e complementada por tabulações de séries temporais e cálculo de indicadores para verificar a evolução dessa relação entre mecanismos de financiamento e capacidade de investimento. Para tanto, além da análise da literatura que perpassa a temática tratada, os principais insumos utilizados foram os documentos administrativos publicados sistematicamente pelos dois principais agentes estudados: o FAT e o BNDES. Foi considerado como horizonte temporal de análise o intervalo de 2005 a 2019, por cobrir um período marcado por mudanças relevantes na dinâmica operacional e contábil tanto do BNDES quanto do FAT, reforçando a relação de complementaridade institucional entre ambos.

O texto está organizado em seis seções, incluindo esta introdução. $\mathrm{Na}$ seção dois, há uma breve discussão sobre o conceito de fundos públicos e sua operacionalidade enquanto capacidade estatal para o desenvolvimento econômico. $\mathrm{Na}$ seção três, destaca-se o papel histórico do BNDES para o financiamento de médio e longo prazo no Brasil. Posteriormente, são apresentadas as características estruturais do FAT e seus mecanismos de disponibilização de recursos para financiar investimentos produtivos e infraestruturais, com ênfase nos canais junto ao BNDES. Na seção cinco, são descritos e discutidos os cálculos de um indicador criado para avaliar a capacidade de geração de fundos emprestáveis gerados anualmente pelo arranjo normativo do FAT. Por fim, são tecidas as consideraçôes conclusivas.

\section{FUNDOS PÚBLICOS E FINANCIAMENTO DO INVESTIMENTO}

Os fundos públicos de poupança compulsória, formados por contribuiçóes de firmas e consumidores domésticos, são instrumentos utilizados em inúmeros países do capitalismo contemporâneo, ganhando maior destaque no cenário pós-Segunda Guerra mundial. ${ }^{3} \mathrm{~A}$ ideia subjacente é mobilizar recursos para a viabilização de investimentos considerados relevantes para infraestrutura e base produtiva nacional que, se por um lado, apresentam alto risco e longo prazo de maturação, com taxa de retorno reduzida durante um período significativo; por outro, possuem externalidades positivas na forma de impactos sobre a demanda agregada e a produtividade (IPEA, 2011; 
ORAIR, 2016). Nesse sentido, o Estado cria capacidades internas para disponibilizar aos investidores fundos emprestáveis com taxas de juros tradicionalmente abaixo daquelas praticadas pelo mercado e com prazo de vencimento alargado, uma vez que o setor público não se pauta exclusivamente por critérios privados de retorno (Bonelli e Pinheiro, 1994).

No caso dos países em desenvolvimento, esse tipo de intervenção também se justifica pelo fato de não haver mercado privado de crédito bem-desenvolvido, o que faz com que o custo do capital tenda a ser relativamente mais elevado. Ademais, a poupança compulsória pode ser usada para levantar contrapartidas domésticas necessárias à contratação de empréstimos concedidos por instituiçóes bilaterais e multilaterais para financiamento de projetos.

Os projetos de interesse ao desenvolvimento econômico financiados por fundos dessa natureza envolvem atividades de diferentes setores e objetivos, tais como: $i$ ) infraestrutura social, a exemplo de saneamento básico (sistemas de água e esgoto) e habitação; ii) infraestrutura urbana (transportes e energia); iii) apoio à pesquisa e à inovação, em busca de incrementos na produtividade e no desenvolvimento de novos produtos; e $i v$ ) geração de postos de trabalho, o que inclui financiamentos a certos setores industriais, micro, pequenas e médias empresas, agricultura familiar, crédito popular, entre outros exemplos. De maneira geral, a disponibilidade desses fundos tende a acompanhar os movimentos cíclicos da economia, sobretudo com relação às receitas (PINHEIRO, 1997, p. 42).

No Brasil, a experiência com fundos públicos alimentados por contribuiçóes sociais de pessoas físicas e jurídicas ganhou maior relevância a partir de meados dos anos 1960. Um dos marcos foi a Lei no 5.107/1966, que estabeleceu o Fundo de Garantia do Tempo de Serviço (FGTS) como compensação pelo fim da estabilidade ao trabalhador que alcançasse mais de 10 anos no mesmo emprego. Os recursos mobilizados pelo FGTS deveriam ser aplicados no financiamento de programas de infraestrutura social, como habitaçóes e saneamento básico. Desde então, outros fundos foram constituídos, distintos entre si na engenharia institucional.

A efetivação desses instrumentos ocorre, tradicionalmente, por meio de bancos públicos, que assumem um papel central enquanto instituiçóes determinantes na trajetória de desenvolvimento nacional, sobretudo em contextos de mercados financeiros incompletos, mais direcionados a projetos de curto prazo e baixo risco (JAYME Jr. \& CROCCO, 2010; HERMANN, 2010; IPEA, 2011; ARAÚJO, 2018). ${ }^{4}$ Dentre os distintos formatos possíveis estão os BPD, utilizados no mundo todo, como o KfW (Alemanha), o Korea Development Bank (Coreia do Sul), o CDB (China), o JFC (Japão) e o próprio BNDES no Brasil (MAZZUCATO \& PENNA, 2015; RODRIGUES, 
AFONSO \& PAIVA, 2017; ALBUQUERQUE, 2018; LEAL \& VIANA, 2019)..$^{5}$

Nesse sentido, pode-se dizer que existe na prática uma relação institucional de complementaridade entre fundos públicos e BPD na construção de canais de financiamento para o desenvolvimento econômico. Para o caso brasileiro, em particular, essa relação será analisada nas seçôes seguintes, com foco no FAT enquanto arranjo complexo de natureza dual, voltado ao tanto para o financiamento de políticas sociais quanto para projetos de investimento, e no BNDES enquanto principal agente operacional do patrimônio financeiro desse fundo.

\section{O BNDES E SUAS ESTRATÉGIAS DE CAPITALIZAÇÃO}

O BNDES desempenha um papel de destaque enquanto agente financiador de longo prazo, presente em praticamente todos os setores da economia brasileira, com empréstimos vinculados a gastos com finalidades específicas (projetos de investimento, exportação de manufaturados e serviços etc.). ${ }^{6}$ Desde sua criação (Lei $\mathrm{n}^{-}$1.628/1952), em plena experiência nacional-desenvolvimentista do segundo governo Vargas, o BNDES passou por diversas estratégias de capitalização, as quais refletem as intençôes de política econômica em cada período. Isso fez com que a participação do banco tanto com relação à formação bruta de capital físico (FBCF), tomada como proxy para o nível de investimento geral da economia, quanto ao nível global do PIB do país, ${ }^{7}$ variassem bastante ao longo do tempo. A tabela 1 apresenta dados sobre essas relações, onde se nota que nos anos recentes houve uma elevação significativa da participação do BNDES nas variáveis reais da economia brasileira, sobretudo a partir de 2005, seguindo de brusca trajetória de queda no quinquênio iniciado em 2015, questão que serão melhor debatidas nas seções posteriores.

Tabela 1 - Médias anuais de participação do BNDES em proporção à FBCF e ao PIB - 1952-2017 (\%)

\begin{tabular}{c|c|c}
\hline Quinquênio & BNDES/FBCF & BNDES/PIB \\
\hline $1952-1956$ & 1,2 & 0,2 \\
$1957-1963$ & 2,5 & 0,4 \\
$1964-1973$ & 4,1 & 0,7 \\
$1974-1978$ & 8,7 & 1,9 \\
$1979-1981$ & 6,5 & 1,5 \\
$1982-1989$ & 7,6 & 1,6 \\
$1990-1994$ & 3,1 & 0,6 \\
$1995-1999$ & 9,6 & 1,6 \\
$2000-2004$ & 11,7 & 2,1 \\
$2005-2009$ & 15,0 & 2,7 \\
$2010-2014$ & 17,1 & 3,5 \\
$2015-2019$ & 7,9 & 1,3 \\
\hline
\end{tabular}

Fonte: Adaptado de Barboza, Furtado e Gabrielli (2019) e Barboza et al. (2020). 
Prochnik (1995) dividiu todo esse histórico operacional em quatro etapas. ${ }^{8}$ Na primeira, entre 1952 e 1967 , o banco contou com recursos do adicional restituível sobre o imposto de renda, além de alguns fundos específicos, tais como: o Fundo de Renovação e Melhoramento das Ferrovias, existente desde 1945; o Fundo Federal de Eletrificação, de 1954; o Fundo de Pavimentação, de 1955; e o Fundo da Marinha Mercante (FMM), criado em 1958 para estimular a marinha mercante e a indústria naval (BNDES, 2017). Durante esse período, o BNDES desempenhou função voltada fundamentalmente para o financiamento de projetos de transportes, energia e siderurgia. Nesse sentido, ele foi "essencial no boom expansivo do Plano de Metas mediante a oferta de créditos de longo prazo em moeda nacional e o aval em empréstimos em moeda estrangeira” (CRUZ, 1994, p. 70).

$\mathrm{Na}$ segunda etapa, entre 1967 e 1973, caracterizado como "fase expansiva" da relação do Estado na condução do desenvolvimento econômico. Foi um período de modernização da estrutura de receita fiscal que culminou na expansão da carga tributária (REZENDE \& AZEREDO, 1986). Nesse contexto, o BNDES passou a integrar o orçamento fiscal e monetário do Tesouro Nacional, sendo a ele destinada parte da reserva monetária constituída pela arrecadação do Imposto sobre Operações Financeiras (IOF). Contudo, havia uma permanente instabilidade no ingresso desses recursos, devido à ocorrência de atrasos nos repasses, que eram compensadas em parte pela entrada de outros recursos vinculados a programas ou projetos específicos (SANTOS, 2006). Destaca-se também uma progressiva mudança nos seus financiamentos, voltando-se cada vez mais para empresas do setor privado.

A terceira etapa, entre 1974 e 1988 , foi marcada pela criação de dois novos fundos patrimoniais do governo federal: o Programa de Integração Social (PIS) e o Programa de Formação do Patrimônio do Servidor Público (Pasep). A arrecadação proporcionada permitiu resolver o problema da irregularidade no fluxo de recursos para funding do banco. Havia também a possibilidade de transferências governamentais, que, embora estivessem previstas no Orçamento, raramente se concretizaram, desempenhando assim um papel residual no financiamento de longo prazo.

Vale destacar ainda a criação do Fundo de Desenvolvimento Social (Finsocial), em 1982, que definiu uma nova dimensão de atuação do BNDES, inclusive com a adoção do "social” ao nome oficial do banco, composto por uma contribuição cobrada às empresas sobre sua receita operacional para o financiamento de programas sociais, sem a exigência de retorno das aplicaçôes. ${ }^{10}$ Porém, as disputas orçamentárias entre os diferentes ministérios por esses recursos comprometeram o saldo para os investimentos previstos originariamente. ${ }^{11}$ 
A quarta etapa tem como marco a CF/1988, que determinou, em seu artigo 239, a destinação de $40 \%$ da arrecadação do PIS-Pasep para o financiamento de programas de desenvolvimento econômico via BNDES, com critérios de remuneração que lhes preservassem o valor. ${ }^{12}$ Essa definição foi confirmada com a Lei no 7.998/1990, que instituiu o FAT enquanto fundo contábil de natureza financeira, sem personalidade jurídica própria (BONELLI \& PINHEIRO, 1994; SILVA, 2018a).

Logo nos primeiros anos, os repasses do FAT chegaram a responder por quase $90 \%$ de todos os novos recursos à disposição do BNDES, contribuindo para que a participação anual média do banco na economia mais que triplicasse entre 1990 e 2000, como mostrado na tabela $1 .{ }^{13}$ Essa participação relativa apresentou mudanças nos anos mais recentes, mas o FAT manteve sua importância estratégica para a atuação do BNDES como agente de desenvolvimento econômico, como mostra a seção seguinte.

\section{A RELAÇÃO INSTITUCIONAL ENTRE FAT E BNDES NO FINAN- CIAMENTO DE PROJETOS DE INVESTIMENTO}

O FAT está previsto no artigo 239 da CF/1988, que definiu um desenho operativo inovador para a implementação de um sistema público de emprego, sendo regulamentado pouco depois, com a Lei no 7.998/1990 (Silva, 2020). Ele é um dos principais fundos públicos geradores de poupança de longo prazo no Brasil, mobilizando anualmente em torno de 1,2\% do PIB. A coordenação de suas decisóes é feita pelo Conselho Deliberativo do Fundo de Amparo ao Trabalhador (CODEFAT) ${ }^{14}$

$\mathrm{Na}$ prática, o FAT funciona como um mecanismo de financiamento dual, que articula, através de uma mesma fonte, dois sentidos diferentes de intervenção: de um lado, a proteção social de trabalhadores desempregados ou de baixa renda (seguro social); de outro, financia projetos de desenvolvimento econômico - o que, em última instância, favoreceria a geração de novos empregos e a ampliação da renda. No primeiro caso, o FAT tem o dever normativo de custear as despesas correntes relativas ao seguro-desemprego e demais políticas de mercado de trabalho, sendo eventualmente complementado por recursos do Orçamento Geral da União. ${ }^{15}$ A vinculação entre fontes e despesas constitui uma garantia de que a União execute as políticas determinadas, evitando a designação dos recursos para outros fins. ${ }^{16} \mathrm{O}$ segundo sentido refere-se à constituição de uma base para operaçóes de crédito voltada a investimentos e capital de giro de empresas (públicas e privadas) via bancos públicos por meio de dois canais: FAT Constitucional e 
Depósitos Especiais. Ambos compóem o patrimônio do FAT, e a remuneração referente às transações é computada como receita financeira.

O FAT Constitucional refere-se à parcela de $40 \%$ do montante líquido arrecadado anualmente através do PIS-Pasep destinada ao BNDES para financiar projetos voltados ao desenvolvimento econômico. conforme expressa a Lei no 7.998/1990. ${ }^{17}$ Ele funciona como uma divida subordinada (TINOCO, BORÇA Jr \& MACEDO, 2018), cujo prazo de exigibilidade do saldo devedor é indefinido, ou seja, não há previsão de devolução do principal, cabendo apenas o pagamento periódico de juros, que é feito semestralmente. Ainda assim, os recursos alocados no FAT Constitucional podem ser resgatados pelo fundo no caso de insuficiência de caixa para o custeio de suas despesas correntes, esgotadas as demais possibilidades.

O BNDES possui livre decisão sobre a aplicação dos recursos advindos do FAT Constitucional. Esse ponto atrai controversas sobre a necessidade de alguma relação de reciprocidade por parte do banco (IPEA, 2011), sobretudo com relação às diretrizes institucionais do sistema público de emprego, trabalho e renda (SPETR) brasileiro. ${ }^{18} \mathrm{~A}$ única exigência concreta é que esses recursos sejam utilizados em programas de desenvolvimento econômico, respeitadas as normas definidas na política operacional do banco (SANTOS, 2006). As principais linhas de aplicação desses recursos são: i) ampliação e diversificação das exportações; ii) reestruturação da indústria; iii) expansão e adequação da infraestrutura a cargo da iniciativa privada, com ênfase nos investimentos em energia e telecomunicações; iv) melhoria dos canais de acesso ao crédito para as micro, pequenas e médias empresas; $v$ ) fortalecimento do mercado de capitais; e vi) atenuação dos desequilíbrios regionais (Brasil, 2020).

No tocante aos setores nos quais os recursos do FAT Constitucional são destinados, a participação do setor de infraestrutura vem crescendo desde 2012, em parte puxado à época pelos investimentos ligados aos grandes eventos, como Copa do Mundo e Olimpíada. Até o final de 2019, o setor respondia por $63 \%$ do total dos desembolsos, como demonstra o gráfico 1. Já em termos regionais, nota-se que a região Sudeste é a que mais obteve financiamentos, com $30,1 \%$ do total, sem desconsiderar o fato de que as regióes Nordeste, Norte e Centro-Oeste também contam com fundos constitucionais próprios. 
Gráfico 1 - Saldo total dos recursos do FAT Constitucional - 2019 (\%)

$1 \mathrm{~A}$ - Por setor de atividade

1,1 Indust. Extrativa $\quad$ 10,5 Agropec./Pesca

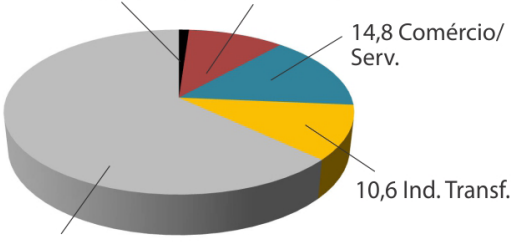

63,0 Infraestrutura
$1 \mathrm{~B}$ - Por região

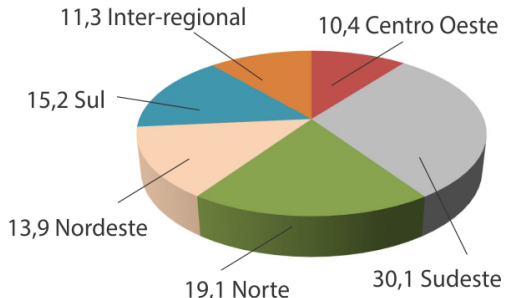

19,1 Norte
30,1 Sudeste

Fonte: Relatório de gestão do FAT - vários anos. (http://portalfat.mte.gov.br/execucao-financeira-do-fat/relatorio-de-gestao-do-fat/)

Além do FAT Constitucional, a Lei no 8.352/1991 estipulou as regras para aplicaçóes de recursos do FAT, com a necessidade de se manter parte das disponibilidades financeiras para a formação de uma Reserva Mínima de Liquidez (RML). Trata-se de um mecanismo a ser utilizado para "garantir, em tempo hábil, os recursos necessários ao pagamento das despesas referentes ao Programa Seguro-Desemprego e ao Abono” (art. 1oㅡ. Os recursos da RML devem ser aplicados em títulos do Tesouro Nacional. Na medida em que há disponibilidade de recursos financeiros que excedam essa reserva, eles podem ser aplicados na forma de Depósitos Especiais, em instituições financeiras públicas, com o objetivo de conceder linhas especiais de crédito a setores com acesso limitado ao sistema financeiro convencional, mas com potencial de geração de novos postos de trabalho e renda. ${ }^{19}$

Contudo, a aplicação de recursos por Depósitos Especiais exige o cumprimento de algumas normas condicionantes por parte dos agentes financeiros. Sua captação também está condicionada à apresentação ao Codefat de um plano de trabalho, no qual devem constar informações detalhadas sobre os objetivos e as condiçốes dos empréstimos a serem concedidos em cada linha de crédito estabelecida.

O prazo de devolução desses recursos é previamente definido sob a forma de Reembolso Automático (RA) na proporção de $2 \%$ do saldo ao mês, com exceção para os recursos aplicados via Programa FAT Infraestrutura, cuja parcela reembolsada é de $1 \%$ ao mês do saldo devedor. O estoque emprestado é remunerado pela taxa de juros de longo prazo, do qual é subtraída posteriormente a parcela amortizada, e os recursos repassados que não forem usados devem ser remunerados pela taxa Selic. Ademais, esses valores podem ser exigíveis a qualquer momento em caso de problemas de caixa para o pagamento do benefício do seguro-desemprego e do abono salarial (SANTOS, 2006; GIAMBIAGI, RIECHE \& AMORIM, 2009). 
O quadro 1, a seguir, apresenta um resumo das características desses dois canais de recursos via arranjo institucional do FAT.

Quadro 1 - Características da principais fontes de financiamento via FAT

\begin{tabular}{|l|l|l|}
\hline Características & FAT Constitucional & Depósitos Especiais \\
\hline Origem & $\begin{array}{l}\text { Repasse de parcela da arrecadação anual da } \\
\text { contribuição para o PIS-Pasep. }\end{array}$ & $\begin{array}{l}\text { Recursos excedentes do } \\
\text { FAT, contratados mediante } \\
\text { apresentação de planos de } \\
\text { trabalho ao Codefat. }\end{array}$ \\
\hline Aplicação & Programas de desenvolvimento econômico. & $\begin{array}{l}\text { Programas e setores } \\
\text { específicos. }\end{array}$ \\
\hline Prazo de exigibilidade & Indefinido. & Definido (PDE). \\
\hline Remuneração* & $\begin{array}{l}\text { TJLP ou dólar + Libor (limitado a 6\% ao ano } \\
\text { para a parcela remunerada em TJLP, sendo } \\
\text { a diferença capitalizada no saldo devedor, } \\
\text { e os juros totais incidentes sobre a parcela } \\
\text { remunerada em Libor). }\end{array}$ & $\begin{array}{l}\text { TJLP ou Selic (para recursos } \\
\text { disponíveis não aplicados). } \\
\text { Pagamento de juros e } \\
\text { amortização (2\% a.m. sobre o } \\
\text { saldo devedor do mês anterior } \\
\text { ou 1\% ao mês no caso do } \\
\text { Programa FAT Infraestrutura). }\end{array}$ \\
\hline
\end{tabular}

Fonte: Adaptado de Santos (2006).

* Com a Lei nº 13.483/2017, o mecanismo básico de remuneração de recursos do FAT passou a ser a Taxa de Longo Prazo (TLP), em substituição à antiga Taxa de Juros de Longo Prazo (TJLP) (ver nota 26).

Em termos de trajetórias de evolução nos últimos anos, as duas modalidades apresentaram dinâmicas diferenciadas. No caso do FAT Constitucional, por ser uma fração fixa da arrecadação primária líquida do FAT, os recursos disponibilizados anualmente estão diretamente relacionados à atividade econômica do país.20 Por isso, o ritmo recente de crescimento dos recursos ficou comprometido com a recessão econômica a partir de 2015. Outra barreira foi a aprovação da Emenda Constitucional (EC) no 476/2016, elevando a Desvinculação dos Recursos da União (DRU) de $20 \%$ para $30 \%$, incidente também sobre o PIS-Pasep, resultando em contração da base de receita primária do FAT (Silva, 2018a).

Já nos Depósitos Especiais houve uma contínua diminuição no montante anual para novos contratos de empréstimos entre 2006, quando a concessão de crédito por essa via alcançou seu maior patamar ( $\$$ 46,8 bilhóes), e 2019, quando se registrou o menor valor da série, com $\mathrm{R} \$ 2,0$ bilhóes, distribuídos em 69,9 mil operações de crédito (média de R \$28,6 mil por operação). Como resultado, enquanto em 2006 esse item representava mais que o triplo do fluxo anual de valores do FAT Constitucional, a relação se inverte drasticamente nos últimos anos, sobretudo a partir de 2010, quando o montante de Depósitos Especiais passa a ser inferior ao FAT Constitucional, com tendência a se tornar uma ação cada vez mais residual. 
O gráfico 2 permite observar a trajetória anual dessas duas modalidades em comparação com a dinâmica recente da formação bruta de capital fixa (FBCP) no Brasil, que além de ser um indicador do nível de investimento na economia, é uma variável fundamental de política econômica, devido seus efeitos multiplicadores sobre a demanda agregada (ORAIR, 2016; FEIJÓ, BRAGA \& CORREAA, 2018). Como se pode ver, a FBCP, medida em proporção do PIB, manteve uma tendência de crescimento até 2014, e a partir de então, apresentou seguidas quedas, fechando a série em um patamar próximo ao de 2005. Observa-se também que a tendência apresentada pela curva de FBCF é bastante similar à do FAT Constitucional, e sua queda pós-2014 coincide com uma reversão abrupta dos desembolsos do BNDES (ver tabela 1 ). ${ }^{21}$

\section{Gráfico 2 - Evolução do fluxo anual de recursos via FAT Constitucional e depósitos especiais, e taxa de FBCP em relação ao PIB (valores de dez./2019, corrigidos pelo IPCA)}

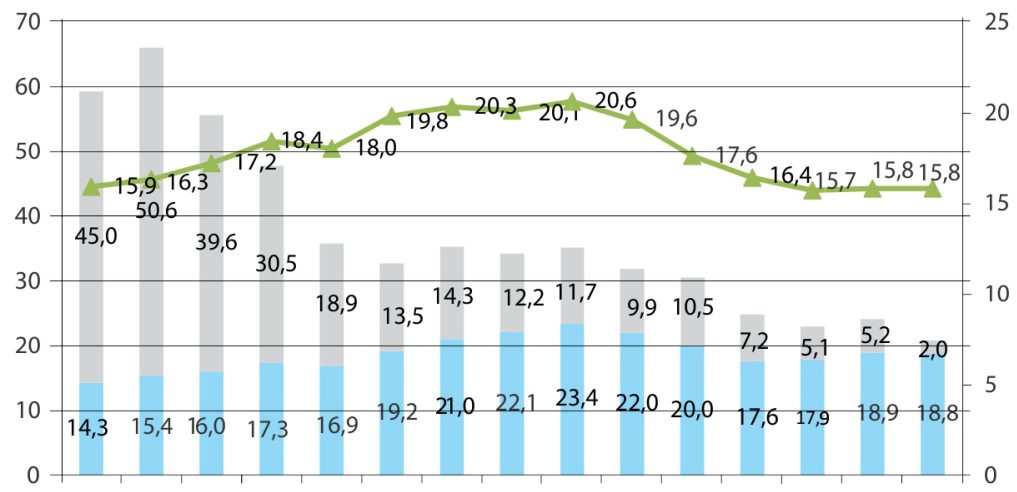

200520062007200820092010201120122013201420152016201720182019

FAT Constitucional (RS Bi) Depósitos Especiais (R\$̧Bi) $\simeq \mathrm{FBCF} / \mathrm{PIB}(\%)$

Fonte: Relatório de gestão do FAT - vários anos.

Há também uma modificação recente na composição do patrimônio do FAT. ${ }^{22}$ Conforme demonstra o gráfico 3, o saldo do FAT Constitucional em poder do BNDES cresceu de $56,5 \%$ para $88,1 \%$ no período entre 2005 e 2019 , representando $\mathrm{R} \$ 282,5$ bilhóes no final da série. Desse montante, $97,1 \%$ são projetos internos, remunerados pela TJLP/TLP, e 2,9\% com projetos produtivos de inserção internacional (FAT Cambial), remunerados pela London Interbank Offered Rate (Libor). Já a participação dos Depósitos Especiais passou por uma queda substantiva, caindo de 37,5\% em 2006 para apenas 3,2\% em 2019, com um saldo de $\mathrm{R} \$ 10,3$ bilhóes no total de financiamentos ativos nesse ano. Por fim, a parcela "extramercado", correspondente ao valor 
destinado à RML, também apresentou uma queda recente, sobretudo a partir de 2018 , fechando a série com $\mathrm{R} \$ 28,0$ bilhôes ou $8,7 \%$ do total de ativos. ${ }^{23}$

Gráfico 3 - Participação por item patrimonial do FAT (2005-2019) (\%)

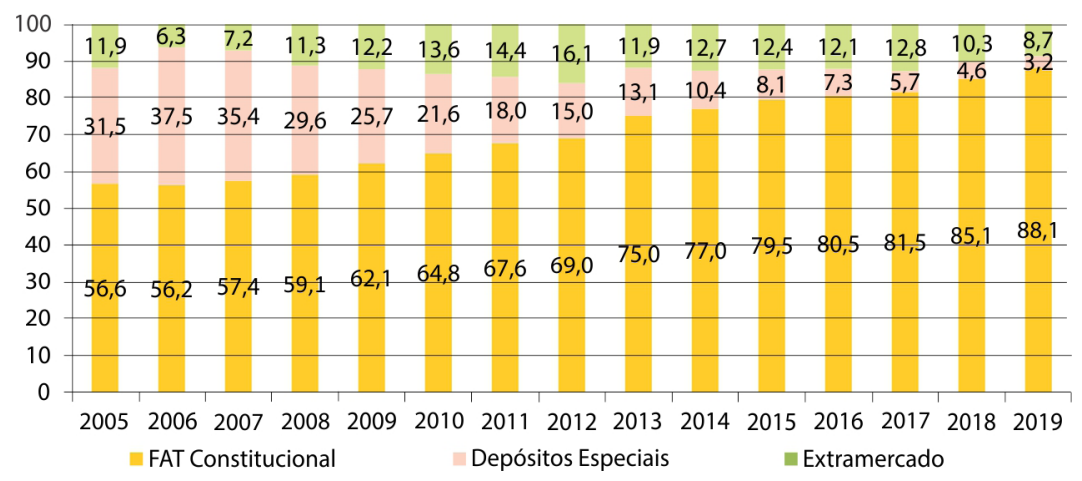

Fonte: Relatório de gestão do FAT - vários anos.

Conforme assinalado anteriormente, todo o montante designado ao FAT Constitucional é operacionalizado pelo BNDES. Já os Depósitos Especiais, embora sejam executados por diferentes agentes financeiros públicos, seu saldo total em 31 de dezembro de 2019 estava concentrado basicamente no BNDES $(75,8 \%)$ e Bando do Brasil (23,9\%). Portanto, o BNDES também mobiliza um percentual bastante elevado dos aportes para apoio a projetos de micro e pequenas empresas via programas do FAT, o que reforça o papel histórico do fundo como canal de funding do BNDES, bem como do BNDES como principal agente operacional dos recursos do FAT para investimentos, reforçando a relação de complementaridade institucional entre esses dois instrumentos de capacidade estatal (AFONSO \& BIASOTO JUNIOR, 2007; IPEA, 2011; SILVA, 2018a).

Porém, embora a capitalização do BNDES via FAT tenha mantido um crescimento constante em termos absolutos na composição dos recursos de terceiros (com exceção de uma pequena queda em 2016), sua participação relativa na estrutura de capital do banco teve uma queda a partir de 2009. Foi quando se iniciou uma política de aportes da União ao BNDES para estimular a economia brasileira no enfrentamento da crise global, sobretudo via a elevação do crédito direcionado para a manutenção de um nível elevado de investimentos sobre o PIB (IPEA, 2011; TINOCO et al., 2018). Com efeito, o período entre 2005 e 2015 foi aquele onde os desembolsos do BNDES apresentaram maior participação no PIB brasileiro, com uma média 3,1\% ao ano (ver tabela 1). 
Essas operações de capitalização não apenas viabilizaram a ampliação da carteira de operações do BNDES, como permitiram a expansão de dividendos pagos à própria União, como um mecanismo adicional de alcance das metas de superávit primário (SCHETTINI et al., 2014; SILVA \& SACCARO, 2019). ${ }^{24}$ Com isso, enquanto em 2006 o FAT representava 52,2\% do total de passivo contra apenas $3,1 \%$ do Tesouro, essa relação se modifica nos anos seguintes, com o Tesouro Nacional chegando a responder em 2013 por $53,2 \%$ (ano de sua maior participação) e o FAT por $21,6 \%$.

Por outro lado, decisões de política econômica também podem implicar queda na capacidade de geração de funding via FAT, na medida em que interferem no seu arranjo de financiamento. As duas ocorrências principais nesse sentido são: por desvinculação de receitas orçamentárias, dispositivo utilizado pelo governo federal desde 1994 para aumentar a discricionariedade de gasto sobre receitas de contribuições sociais, como ocorre atualmente via DRU; e por desoneraçóes tributárias, quando são concedidas isençôes ou abatimentos de alguns tributos (dentre eles o PIS-Pasep) a setores específicos, afetando seu potencial arrecadatório. Silva (2018a) classificou esses dispositivos como "vazamentos" de receitas, que tanto comprometem a capacidade do FAT em honrar com as obrigações programáticas que lhes são definidas (financiamento do SPETR), quanto limita o volume de recursos transferidos para o financiamento de projetos de investimento.

Com a reversão do crescimento econômico a partir de 2015, houve um redirecionamento da política fiscal, em virtude da decisão governamental de não apenas frear o aporte de recursos via Tesouro Nacional, como também solicitar a amortização dos repasses já concedidos, realizado por meio da devolução do montante retido do passivo junto ao Tesouro. Esse movimento gerou uma queda abrupta da capacidade de atuação do BNDES, com queda de $33,9 \%$ em seu passivo circulante entre 2015 e 2019, conforme mostrado anteriormente na tabela 2. Ademais, a própria participação do BNDES na economia nacional caiu drasticamente nesse período, com uma média de 1,3\% ao ano em relação ao PIB (ver tabela 1), sendo que em 2019 foi de apenas $0,8 \%$, menor patamar nas últimas três décadas.

Com isso, os mecanismos de empréstimo constitucional do FAT aumentaram sua importância relativa tanto na estrutura de capital quanto na fonte de recursos (fluxo de caixa anual) do BNDES, de modo que a sustentabilidade do fundo voltou a ter grande importância para as atividades do banco. Em 2019, o FAT voltou a ser o principal credor em sua estrutura de capital, como demonstra o gráfico 4, cujos dados permitem uma análise comparativa para o período entre 2005 e $2019 .{ }^{25}$ 
Tabela 2 - Evolução dos principais componentes no passivo do BNDES (Em bilhões - valores de dez./2019, corrigidos pelo IPCA)

\begin{tabular}{c|c|c|c|c|c|c|c|c}
\hline Ano & $\begin{array}{c}\text { FAT } \\
\text { Constituc. }\end{array}$ & $\begin{array}{c}\text { Dep. } \\
\text { Esp. }\end{array}$ & Total & $\begin{array}{c}\text { PIS-Pasep } \\
(1)\end{array}$ & $\begin{array}{c}\text { Tesouro } \\
\text { Nacional }\end{array}$ & $\begin{array}{c}\text { Patrim. } \\
\text { Líquido }\end{array}$ & Outras & $\begin{array}{c}\text { Total } \\
\text { Passivo }\end{array}$ \\
\hline 2005 & 126,3 & 39,8 & 166,1 & 43,0 & 29,8 & 30,1 & 66,2 & 335,3 \\
\hline 2006 & 135,2 & 46,8 & 181,9 & 45,5 & 10,7 & 35,5 & 74,8 & 348,3 \\
\hline 2007 & 138,1 & 45,9 & 184,0 & 47,2 & 14,3 & 44,4 & 70,7 & 360,4 \\
\hline 2008 & 149,1 & 41,9 & 191,0 & 47,1 & 60,2 & 42,4 & 125,0 & 465,7 \\
\hline 2009 & 155,8 & 37,0 & 192,8 & 45,5 & 209,3 & 44,5 & 130,3 & 622,4 \\
\hline 2010 & 163,7 & 32,8 & 196,5 & 44,0 & 358,3 & 100,2 & 135,5 & 834,5 \\
\hline 2011 & 173,8 & 30,1 & 203,9 & 42,2 & 421,2 & 87,1 & 137,4 & 891,7 \\
\hline 2012 & 185,7 & 24,9 & 210,6 & 41,2 & 482,7 & 70,3 & 160,0 & 964,8 \\
\hline 2013 & 194,7 & 22,1 & 216,8 & 40,5 & 500,4 & 77,2 & 160,8 & 995,7 \\
\hline 2014 & 209,0 & 17,7 & 226,7 & 38,1 & 558,5 & 79,3 & 147,1 & 1049,7 \\
\hline 2015 & 237,5 & 15,5 & 252,9 & 37,4 & 573,4 & 36,7 & 198,9 & 1101,8 \\
\hline 2016 & 238,2 & 12,8 & 251,1 & 34,3 & 447,8 & 61,5 & 181,4 & 976,0 \\
\hline 2017 & 258,5 & 10,9 & 269,3 & 28,1 & 409,5 & 68,0 & 164,0 & 938,8 \\
\hline 2018 & 273,6 & 10,1 & 304,8 & 21,1 & 320,2 & 83,0 & 108,0 & 837,1 \\
\hline 2019 & 282,5 & 7,8 & 310,4 & 20,1 & 199,7 & 104,8 & 93,2 & 728,2 \\
\hline
\end{tabular}

Fonte: Relatórios de Demonstração Financeira do BNDES - vários anos.

(https://www.bndes.gov.br/wps/portal/site/home/conhecimento/publicacoes/relatorios).

(1) Recursos dos fundos PIS-Pasep anteriores à CF/1988. Não conta com novas entradas e tende à extinção.

Gráfico 4 - Principais componentes no capital de terceiros do BNDES (\%)

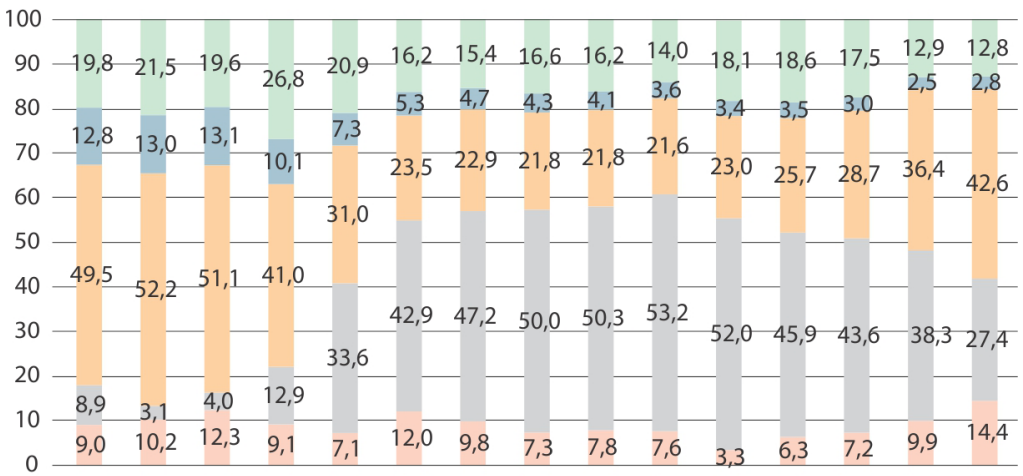

200520062007200820092010201120122013201420152016201720182019

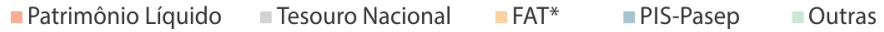

Fonte: Relatórios de Demonstração Financeira do BNDES - vários anos. 
Portanto, a relação de importância do FAT como mecanismo gerador de funding ao BNDES depende tanto de sua dinâmica contábil anual, no que se refere a sua capacidade de honrar obrigaçóes de política social definidas constitucionalmente, quanto de decisóes de política econômica, que podem afetar diretamente o fluxo de receitas correntes, comprometendo assim a oferta de financiamentos de longo prazo. Essas duas possibilidades, por sua vez, também interferem na capacidade do arranjo institucional do FAT de gerar recursos para financiar o investimento no país, conforme debatido na seção seguinte.

\section{CALCULANDO A CAPACIDADE DE INVESTIMENTO DO FAT}

A incumbência de ser um instrumento estável tanto para o financiamento das políticas de proteção aos trabalhadores quanto para projetos de investimento confere ao FAT um papel importante em termos de trajetória de desenvolvimento, basicamente por dois motivos. Em primeiro lugar, os gastos sociais possuem impacto direto no consumo e no bem-estar das famílias, além de contribuir com a redução das desigualdades sociais (GENTIL \& ARAÚJO, 2012; NERI, VAZ \& SOUZA, 2013). Segundo, os investimentos podem ser considerados o principal canal de influência do gasto público total sobre o crescimento da economia, devido a seu fator multiplicador e sua capacidade de geração de demanda agregada por meio de efeito crowding in (GENTIL \& HERMANN, 2015; ORAIR, GOBETTI \& SIQUEIRA, 2016; ORAIR, 2018).

Ademais, enquanto fonte para investimentos de longo prazo, os recursos mobilizados pelo FAT favorecem a melhoria da infraestrutura, o que reflete diretamente no processo de desenvolvimento e diversificação produtiva na economia nacional. Como pontuou Carneiro (2007, p. 50-51):

A infraestrutura é responsável pela indução do investimento nos demais setores da economia por duas razôes: a primeira delas é a redução da incerteza ao assegurar a disponibilidade de insumos de uso geral, como energia elétrica ou bens públicos, como estradas. Por sua vez, aumenta a competitividade sistêmica e permite ampliar a lucratividade do investimento ao reduzir custos de produção. Nesse último caso, a ampliação da infraestrutura desempenha papel equivalente ao do progresso técnico em atividades industriais.

No entanto, os desequilíbrios contábeis do FAT em seus últimos balanços anuais além de comprometerem a continuidade de programas de proteção dos trabalhadores e incentivo à geração de emprego e renda, colocam em xeque também seu outro objetivo, que é financiar projetos de desenvolvimento econômico. Com o conjunto de decisóes de política fiscal ao longo 
dos anos que acarretaram contínuos vazamentos em sua estrutura de receitas, diminuindo tanto a base de cálculo para o repasse ao BNDES via FAT Constitucional quanto as disponibilidades de recursos para novos Depósitos Especiais, como mostrado no gráfico 2, sua capacidade de fomento ao investimento produtivo no país também se reduz. Dessa forma, como o fundo fomenta esses distintos tipos de gastos, a preocupação com sua sustentabilidade passa a ser um elemento bastante relevante no debate atual sobre estratégias de desenvolvimento (SILVA, 2018a; 2018b).

Para acompanhar essa relação, optou-se por criar um índice de capacidade de investimento (ICI), tendo como referência o fluxo de caixa do FAT em cada ano no período em análise, conforme apresentado em Apêndice. O ICI é dado pelas seguintes equaçóes:

(1) $T L R_{t}=\left(P P_{t}+R F_{t}+O R_{t}\right)-A T_{t}$

(2) $T D C_{t}=S D_{t}+A S_{t}+O D_{t}$

(3) $V R M L_{t}=\left[\left(S D_{t}+A S_{t}\right)-\left(S D_{t-1}+A S_{t-1}\right)\right] / 2$

(4) $I C I_{t}=T L R_{t}-T D C_{t}-R M L_{t}$

(5) $I C I^{*}=I C I_{t}+D R U_{t}$

Onde:

- ICI: fluxo da capacidade de investimento;

- ICI*: ICI calculado sem a incidência da DRU;

- TLR: total líquido de receitas correntes;

- TDC: total de despesas correntes;

- VRML: variação da reserva mínima de liquidez;

- PP: arrecadação líquida do PIS-Pasep;

- DRU: recursos desvinculados;

- RF: remuneraçốes financeiras das aplicaçốes;

- OR: outras receitas;

- AT: aportes do Tesouro Nacional;

- SD: despesas com o seguro-desemprego;

- AS: despesas com o abono salarial;

- OD: outras despesas;

A formulação do ICI parte de um princípio simples. O fluxo da capacidade de investimento anual gerado pelo arranjo de financiamento do FAT no ano de referência (equação 4) é igual ao seu total líquido de receitas correntes, excluindo-se os aportes do Tesouro Nacional (equação 1), menos o total de despesas correntes (equação 2) e menos a variação da RML (equação 3). Pensado de outra forma, é o resultado entre o total repassado ao BNDES (FAT Constitucional) mais o resultado nominal do exercício contábil, debitados os 
aportes do Tesouro Nacional e a variação da RML. Para fins destes cálculos, a RML foi simulada como a metade dos gastos somados com seguro-desemprego e abono salarial nos últimos doze meses, conforme Lei no 8.352/1991, corrigidos para o valor do ano corrente.

Com isso, buscou-se uma medida que indique anualmente o incremento de recursos líquidos disponíveis para fins de políticas de investimento. $\mathrm{Ou}$ seja, o ICI refere-se ao valor potencial a ser acionado na dinâmica econômica via financiamento de novos investimentos em um determinado exercício contábil.

O gráfico 5 permite visualizar as trajetórias e os valores do ICI calculado e do ICI* para o período 2005 a 2019, comparando-as com a curva do resultado operacional de cada exercício. Percebe-se que as taxas de variação entre as linhas de ICI e de ICI* variam de forma semelhante até 2016, quando a alíquota da DRU sobre a arrecadação do PIS-Pasep passou de 20\% para 30\% (EC no 476/2016), o que explica a queda mais acentuada da curva do ICI nesse ano. Já a curva de resultado operacional segue trajetória semelhante às demais até 2011, pois no ano seguinte o fluxo de caixa passou a receber aportes substanciais do Tesouro Nacional, causando variaçóes nos anos seguintes, uma vez que esses aportes não seguem uma regra específica. Vale ressaltar, porém, que somente em 2014 o valor dos aportes do Tesouro foi superior ao retido pela DRU, o que explica esse encontro entre as curvas do resultado operacional e ICI*. Em 2016 e 2017, anos marcados por queda drástica nas receitas primárias do fundo, o resultado líquido do ICI também ficou abaixo do resultado operacional contábil desses anos.

Gráfico 5 - Evolução do ICl e do resultado Nominal do FAT (2005-2019)

(Em milhões - valores de dez./2019, corrigidos pelo INPC)

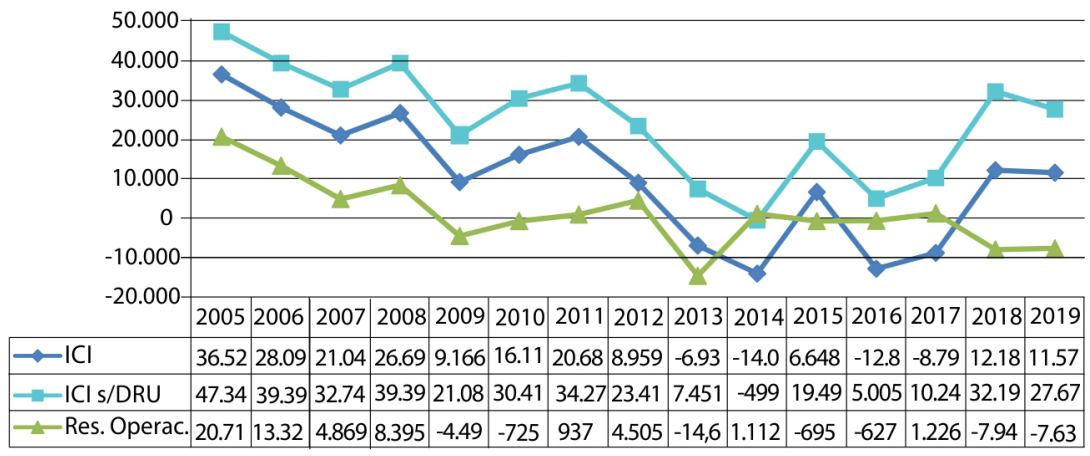

Fonte: Relatório de gestão do FAT - vários anos. 
Exclusivamente sobre o ICI, percebe-se que ele apresentou grande volatilidade durante o período. Há queda significativa em 2009, devido à diminuição de receitas em função da crise econômica mundial deflagrada no ano anterior. Após breve recuperação, o ICI voltou a cair, de forma mais acentuada, a partir de 2012, ano em que a despesa corrente cresceu $10,1 \%$, enquanto a arrecadação primária caiu 2,0\%. As despesas mantiveram um ritmo similar de crescimento até 2015, quando as novas regras para o seguro-desemprego e o abono salarial (Lei no 13.134/2015) diminuíram o gasto corrente com esses programas. Já a arrecadação primária continuou em queda, influenciada tanto pelo arrefecimento da dinâmica de crescimento do PIB quanto por mudanças nas decisões políticas sobre desoneraçóes tributárias e da DRU, apesar de pequena recuperação $(3,4 \%)$ em $2017 .{ }^{26} \mathrm{~A}$ variação acentuada entre 2015 e 2016 também é explicada em parte pelo atraso no cronograma de pagamento do abono salarial de 2015 (SILVA 2018a; 2019a), quando cerca de metade dos benefícios foi paga somente no ano seguinte, comprometendo o fluxo anual de despesas correntes. A partir de 2017 observa-se uma recuperação do ICI, em função de uma trajetória moderada de queda nas despesas correntes e incremento nas receitas primárias.

Em três anos o resultado do ICI foi negativo: 2013, 2016 e 2017. Isso não implica dizer que não houve utilização dos recursos do FAT em desembolsos para financiamento de projetos de investimento. A parcela constitucional dos $40 \%$ do PIS-Pasep - após descontada a DRU - foi repassada nesses anos ( $\mathrm{R} \$ 23,8, \mathrm{R} \$ 18,0$ e $\mathrm{R} \$ 17,9$ bilhóes, respectivamente). O que o índice aponta é que a soma do valor das demais obrigaçóes - do resultado nominal (negativo nos dois anos), do aporte do Tesouro e da variação na RML - superou o total repassado ao BNDES. Contudo, os resultados negativos são explicados em grande medida pelos "vazamentos" de receita sofridos pelo FAT, somando-se as desvinculações orçamentárias e as isenções tributárias que afetaram fortemente suas receitas, conforme demonstrado por Silva (2018a). Somente com a incorporação da DRU, com a curva ICI*, já i que indica apenas 2014 como resultado negativo, e ainda assim relativamente baixo.

Portanto, nesse trajetória de redução da margem financeira do FAT para a destinação de recursos emprestáveis nos últimos anos, o cenário analisado impõe preocupações relevantes sobre a manutenção do arranjo de financiamento do FAT, sobretudo em um contexto de incertezas como o atual, marcado por uma forte queda da taxa de investimento na economia - 20,6\% do PIB em 2013 para 15,8\% em 2019 (gráfico 2) - e reversão da trajetória de incorporação da força de trabalho via assalariamento formal a partir de 2015 (Silva, 2017a; 2017b; Oliveira e Silva, 2018), afetada ainda mais pelos efeitos nefastos da pandemia de Covid-19 na economia nacional em 2020 
(Ipea, 2020). Além de ter seu potencial de fomentar políticas de ativação do mercado de trabalho - como a intermediação de emprego e a qualificação profissional - reduzida, e contar com cada vez menos espaço para financiamento de programas de trabalho e renda via crédito, os resultados recentes do fluxo financeiro do FAT (que resultam de uma combinação entre desenho institucional, dinâmica da economia e decisóes de política fiscal) caminham a uma situação na qual mesmo sua característica de fundo dual encontra-se comprometida. ${ }^{27}$ Tal prognóstico teria consequências nitidamente negativas para a sustentabilidade do fundo, pois não apenas diminuiria sua capacidade de geração de investimento na economia como comprometeria suas receitas financeiras futuras advindas desse patrimônio.

\section{CONCLUSÃO}

A discussão aqui apresentada baseou-se na dinâmica de complementaridade institucional envolvendo o FAT e o BNDES, tanto para a disponibilização de recursos financeiros quanto para a operacionalização de investimentos necessários ao desenvolvimento nacional, com foco no nível de emprego e demanda agregada e na elevação da produtividade e das expectativas de crescimento sustentado. Como visto, o FAT manteve, desde sua criação em 1990, uma participação bastante relevante na estrutura de capitais do banco, embora em termos relativos essa participação tenha variado ao longo dos anos em função de decisões de política econômica, especialmente no contexto pós-crise do capitalismo mundial em 2008.

A elaboração de um índice para acompanhar as variaçóes anuais na capacidade de financiamento gerada pelo arranjo do FAT permitiu não apenas avaliar o incremento de recursos líquidos efetivamente disponíveis para fins de políticas de investimento, mas também problematizar a interferência de variáveis macroeconômicas reais - captadas pelo exercício contábil do fundo - e decisões de política fiscal sobre seu potencial gerador. A instabilidade observada de tal trajetória gera preocupaçóes em termos de planejamento econômico, dada a importância do FAT na geração de funding para o BNDES, que, por sua vez, possui atuação consolidada como maior agente financiador de médio e longo prazo no país.

Nesse sentido, qualquer decisão política que interfira nos mecanismos de financiamento já estabelecidos deve levar em consideração essa relação de complementaridade, pois existem sérias incertezas sobre o potencial do mercado financeiro privado em assumir o papel de financiador de longo prazo na economia brasileira, dadas as características próprias desse mercado já amplamente debatidas na literatura. Os números mais recentes demons- 
tram que a queda na geração de fundos de longo prazo via esse arranjo entre FAT e BNDES foi acompanhada pela queda no nível agregado de investimentos na economia brasileira, embora não tenha sido interesse deste trabalho verificar estatisticamente a existência de uma relação de causalidade entre essas variáveis.

Por isso, entende-se que o ICI, conforme exposto neste estudo, pode ser um indicador válido para o acompanhamento da dinâmica financeira anual do FAT, por incorporar um conjunto amplo de informações em um índice de simples manipulação para fins analíticos. Contudo, vale ressaltar que se trata de um indicador potencial - ou seja, os recursos mobilizados por esse arranjo institucional não necessariamente se convertem em investimentos na sua totalidade. Existem outros fatores determinantes para o nível de investimento na economia, que implicam a tomada de decisões por parte de agentes públicos e privados. Ainda assim, o entendimento defendido neste texto é que a existência de fundos e instituiçóes financeiras desenhados e capacitados para viabilizar projetos dessa natureza são fundamentais para a pavimentação de estratégias em busca de níveis desejados de investimento para o desenvolvimento nacional, em suas múltiplas dimensóes.

\footnotetext{
Notas

1 O conceito de capacidades estatais assumido neste texto refere-se ao poder do Estado de mobilizar recursos e instrumentos institucionais necessários para estabelecer objetivos de políticas e transformá-los em intervenções práticas na dinâmica social de um dado território (GOMIDE \& PIRES, 2014).

2 Duas instituições podem ser complementares quando a atividade de uma potencializa a eficiência e a manutenção de outra (HALL \& SOSKICE, 2001).

3 Essas receitas diferem de impostos puros, uma vez que os contribuintes têm direito a parte dos lucros desses fundos, que diferem da poupança comum porque os agentes são obrigados a contribuir (BONELLI \& PINHEIRO, 1994).

4 Vale ressaltar que, no Brasil, cerca de $90 \%$ de todo o estoque dos recursos bancários destinados a financiamentos com prazo de pagamento acima de cinco anos está em ativos dos bancos públicos (BNDES, 2017).

5 Em 2011 havia registros de 288 bancos de desenvolvimento em todo o mundo, concentrados principalmente no sul e leste da Ásia (29,5\%), na África (24,3\%) e na América Latina (17,7\%). Sua utilização enquanto instrumento contra cíclico e fonte complementar ao mercado de capitais e ao sistema de crédito comercial ganhou novo impulso após a crise financeira internacional de 2008, principalmente na operacionalização de políticas de afrouxamento monetário (quantitative easing) em países desenvolvidos para combater os efeitos da crise (MUSACCHIO \& LAZZARINI, 2015). Já no Brasil existem atualmente quatro bancos de desenvolvimento, sendo três regionais (BRDE, Bandes e BDMG) e um nacional (BNDES), além de 16 agências de fomento - instituições financeiras não bancárias controladas pelas unidades da federação (FEIJÓ, HORN \& FEIL, 2020).

6 Em 2016, o BNDES respondeu por mais de 50\% dos empréstimos com prazos superiores a cinco anos no Brasil.

7 Para uma análise recente sobre a relação entre investimentos públicos e ciclos econômicos, ver Orair (2016).

8 Para uma análise histórica do BNDES, ver também (BARBOZA, FURTADO \& GABRIELLI, 2019).
} 
9"Para evidenciar tal mutação, basta lembrar que até o golpe militar o setor público havia absorvido cerca de $90 \%$ dos recursos liberados pelo BNDE, enquanto que por época do II Plano Nacional de Desenvolvimento (PND) esse percentual estava reduzido a menos de 20\%" (CRUZ, 1994, p. 70).

10 Com a CF/1988, o Finsocial passou a integrar o orçamento da seguridade social, adotando a denominação de Contribuição para Financiamento da Seguridade Social (Cofins).

11 “Estima-se que, no período 1982/1984, o desgaste financeiro dos recursos transferidos ao BNDES tenha sido em torno de $50 \%$. Isto se deve principalmente às retenções nos cofres da União, tendo em vista os interesses mais imediatos das políticas fiscal e monetária" (REZENDE \& AZEREDO, 1986, p. 13).

12 Durante essa etapa, o BNDES também atuou na coordenação do processo de privatizações nos anos 1990, inclusive mantendo-se como acionista minoritário em algumas empresas (ver MUSACCHIO \& LAZZARINI, 2015).

13 Para um diagnóstico mais recente da relação entre desembolsos do BNDES e FBCP, ver Puga e Gabrielli (2018), que encontraram uma correlação positiva entre os dois.

14 Para uma análise mais aprofundada do Codefat, ver Silva (2018b).

15 As despesas correntes no âmbito do SPETR referem-se aos programas de: i) seguro-desemprego; ii) abono salarial; iii) intermediação de emprego; iv) certificação e orientação profissional; v) qualificação social e profissional; vi) fomento às atividades empreendedoras; e vii) informações sobre o mercado de trabalho.

16 Sobre o conjunto de políticas financiadas historicamente pelo arranjo institucional de financiamento do FAT, ver Azeredo (1998) e Silva (2018a).

17 Vale destacar que, com a aprovação da Emenda Constitucional no 103/20190, que tratou da reforma da previdência, o percentual anual de repasses do FAT ao BNDES foi reduzido de $40 \%$ para 28\%, passando também a não mais ser aplicado o desconto referente à DRU sobre a arrecadação do PIS/Pasep.

18 O SPETR brasileiro foi construído historicamente com base nas Convenções da Organização Internacional do Trabalho (OIT) já ratificadas pelo governo brasileiro. Sobre esse processo, ver Silva (2020).

19 Tais programas de crédito começaram a ser operacionalizados gradualmente em 1995 por agentes financeiros públicos, como o Banco do Brasil, o Banco do Nordeste (BNB), a Financiadora de Estudos e Projetos (Finep), a Caixa, o Banco da Amazônia (Basa) e o próprio BNDES. Entre os mais populares estão o Programa de Geração de Emprego e Renda (Proger) e o Programa Nacional de Fortalecimento da Agricultura Familiar (Pronaf).

20 Atualmente, as alíquotas incidem, no caso do PIS, sobre o faturamento das pessoas jurídicas de direito privado $(1,65 \%)$ ou sobre a folha de salários das entidades sem fins lucrativos (1\%) e, no caso do Pasep, sobre as receitas arrecadadas e transferências recebidas pelas pessoas jurídicas de direito público (1\%) (BNDES, 2017).

21 Segundo Barboza, Furtado \& Gabrielli (2019), os desembolsos do BNDES caíram de R\$ 261,7 bilhões no acumulado em 2014 para R\$ 71,7 bilhões em 2017, voltando para um nível similar ao de 1998.

22 Para uma análise mais pormenorizada da dinâmica contábil do FAT, ver Silva (2018a).

23 Vale mencionar que o cálculo do patrimônio do FAT para estes fins não está levando em conta outras rubricas, como ativo imobilizado, a receber, entre outros, que somados representaram $\mathrm{R} \$ 28,8$ bilhões em 2019, valor próximo ao montante aplicado extramercado.

24 Como resultado desse movimento, entre 2007 e 2016 ocorreu forte crescimento do crédito para as firmas em proporção do PIB, que passou de 16,6\% em 2007 para 28,5\% em 2016, basicamente devido ao aumento do crédito direcionado do BNDES (SILVA \& SACCARO, 2019). Para uma revisão da literatura sobre impactos do BNDES em várias dimensões da economia brasileira (tempo de sobrevivência de empresas contempladas, crescimento do emprego e das exportações, desmatamento, finanças públicas, etc.), ver De Negri et al. (2018) e Barboza et al. (2020).

25 O crescimento observado do patrimônio líquido em 2019 reflete os efeitos do lucro líquido de R\$ 17,7 bilhões no exercício e do ajuste de avaliação patrimonial positivo dos títulos disponíveis para venda, que alcançou R\$ 8,814 bilhões no ano, atenuados pela antecipação de dividendos de R\$ 7,953 bilhões, apurados sobre o lucro do primeiro semestre de 2019. Em 2019, houve aumento de R\$2,550 bilhões do capital social por meio da incorporação integral da reserva para aumento de capital (BNDES, 2020).

26 Para mais detalhes, verificar dados no apêndice.

27 Uma proposta recente de reformulação do arranjo de financiamento e de operacionalização dos programas associados ao FAT pode ser conferida em Silva (2018b). 


\section{Referências}

AFONSO, José R. \& BIASOTO JUNIOR, Geraldo. Investimento público no Brasil: propostas para desatar o nó. Revista Novos Estudos, São Paulo, n.77, pp.8-27, 2007.

ALBUQUERQUE, B. E. et al. Os bancos de desenvolvimento e o papel do BNDES. Rio de Janeiro: BNDES, 2018. (Textos para Discussão n. 133).

ALÉM, A. C.; MADEIRA, R. F. \& MARTINI, R. A. Sistemas nacionais de fomento. In: ABDE-BID. Prêmio ABDE-BID. Rio de Janeiro, $\mathrm{ABDE}, 2015$.

AMSDEN, A. The rise of the rest: challenges to the west from late-industrializing economies. New York: Oxford University Press, 2001.

ARAÚJO, V. L. Bancos públicos de desenvolvimento: uma aproximação teórica. Revista Análise Econômica, v. 36, n. 70, p.7-33، 2018.

ARAÚJO, V. L. \& CINTRA, M. O papel dos bancos públicos federais na economia brasileira. Brasília: Ipea, 2011. (Texto para Discussão, $n^{\circ}$ 1604).

AZEREDO, B. Políticas públicas de emprego. São Paulo: ABET, 1998.

BARBOZA, R. M. \& FURTADO, M. \& GABRIELLI, H. A atuação histórica do BNDES. Revista de Economia Política, v. 39, n. 3, 2019.

BARBOZA, R. M. et. al. O que aprendemos sobre o BNDES? Rio de Janeiro: BNDES, 2020. (Texto para Discussão, n. 149)

BNDES - BANCO NACIONAL DO DESENVOLVIMENTO. Relatório anual integrado 2019. Rio de Janeiro: BNDES, 2020.

BONELLI, R. \& PINHEIRO, A. C. O papel da poupança compulsória no financiamento do desenvolvimento. Revista do BNDES, v.1., n.1. pp.17-36, 1994.

BRASIL. Relatório de gestão do FAT: exercício de 2016. Brasília: MTE/CGFAT, 2017.

CALDERÓN, C. \& SERVEN, L. The effects of infrastructure development on growth and income distribution. Washington: World Bank, 2004.
CALDERÓN, C. \& CHONG, A. Volume and quality of infrastructure and the distribution of income: an empirical investigation. Review of Income and Wealth, v. 50, n. 1, 2004.

CARNEIRO, R. M. Dinâmica de crescimento da economia brasileira: uma visão de longo prazo. Campinas: Unicamp, 2007. (Texto para Discussão, n. 130).

CHANG, H. J. The economic theory of the developmental state. In: WOO-CUMINGS, M. (Org.). The developmental state. New York: Cornell University Press, 1999.

CINTRA, M. \& PRATES, D. M. Fundos de poupança compulsória como instrumentos de funding na economia brasileira. In: JAYME Jr.; Frederico G.; CROCCO, Marco (Orgs.). Bancos públicos e desenvolvimento. Brasília: IPEA, 2010.

CRUZ, P. R. C. Notas sobre o financiamento de longo prazo na economia brasileira do após-guerra. Revista Economia e Sociedade, v1, n.3, p.65-80, 1994.

DEMETRIADES, P. \& MAMUNEAS, T. P. Intertemporal output and employment effects of public infrastructure capital: evidence from 12 OECD economies. Economic Journal, v. 110, n. 465, pp. 687-712, 2000.

DE NEGRI, J. A. et al. (Orgs.). Financiamento do desenvolvimento no Brasil. Brasília: IPEA, 2018.

ESFAHANI, H. \& RAMIREZ, M. T. Institutions, infrastructure and economic growth. Journal of Development Economics, v. 70, pp. 443-477, 2003.

ESTACHE, A.; FOSTER, V. \&WODON, Q. Accounting for poverty in infrastructure reform. Washington: The World Bank, 2002.

FEIJO, C.; BRAGA, J. M. \& CORRÊA, M. F. Developmentalism and the determinants of investment: an econometric exercise for Brazil in the 2000s. Brazilian Keynesian Review, 4(2), pp. 250-277, 2018.

FEIJO, C.; HORN, C. H. \& FEIL, F. Por que precisamos de instituições de financiamento público para retomar o desenvolvimento pós pandemia. Boletim Finde, n. 2, 2020. 
GENTIL, D. \& ARAÚJO, V. L. Mais além da macroeconomia de curto prazo. Rio de Janeiro: UFF, 2012. (Texto para Discussão, n. 289).

GENTIL, D. \& HERMANN, J. Política fiscal no governo Dilma Rousseff. In: VIII Encontro Internacional da associação Keynesiana Brasileira, 8, Anais... Uberlândia, 2015.

GIAMBIAGI, F.; RIECHE, F. \& AMORIM, M. As finanças do BNDES. Revista do BNDES, v.16, n.31, p. 3-40, 2009.

GOMES, J. W.; PEREIRA, R. A. \& BEZERRA, A. R. Efeitos distributivos do aumento nos investimentos públicos em infraestrutura no Brasil. Revista Pesquisa e Planejamento Econômico, v. 49, n. 2, 2019.

GOMIDE, A. \& PIRES, R. R. (Orgs.). Capacidades estatais e democracia. Brasília: IPEA, 2014.

HALL, P. A. \& SOSKICE D. (Eds.). Varieties of capitalism: the institutional foundations of comparative advantage. Oxford: Oxford University Press, 2001.

HERMANN, J. Desenvolvimento financeiro e concorrência privada. In: JAYME Jr.; Frederico G.; CROCCO, Marco (Orgs.). Bancos públicos e desenvolvimento. Brasília: IPEA, 2010.

IPEA. Bancos de desenvolvimento e mercados de capitais. In: IPEA. Brasil em Desenvolvimento 2011. Brasília: Ipea, 2011. (v. 2)

JAYME Jr.; F. G. \& CROCCO, M. (Orgs.). Bancos públicos e desenvolvimento. Brasília: IPEA, 2010.

JOHNSON, C. MITI and the Japanese miracle: the growth of industrial policy, 19251975. Stanford: Stanford University Press, 1982.

LEAL, R. M. \& VIANA, M. E. Financiamento do desenvolvimento sustentável: elementos para a contribuição dos bancos de desenvolvimento. Revista do BNDES, v. 26, n. 52, 2019.

MAZZUCATO, M. \& PENNA, C. The rise of mission-oriented state investment banks: the cases of Germany's KfW and Brazil's BNDES. Sussex: 2015. (SPRU Working Paper Series, n. 26)
MUSACCHIO, A. \& LAZZARINI, S. G. Reinventando o capitalismo de estado. São Paulo: Portfolio-Penguin, 2015.

NERI, M. C. \& VAZ, F. M. \& SOUZA, P. H. F. Efeitos macroeconômicos do Programa Bolsa Família: uma análise comparativa das transferências sociais. In: CAMPELLO, T.; NERI, M. C. (Ed.). Programa Bolsa Família. Brasília: Ipea, 2013.

OLIVEIRA, T. \& SILVA, S. P. Regulação e dinâmica do mercado de trabalho. In: CARDOSO JÚNIOR, José C. (Org.). A Constituição golpeada: 1988-2018. São Paulo: Perseu Abramo, 2018.

ORAIR, R. Política fiscal no Brasil contemporâneo: investimento público e ciclos econômicos. In: GOMIDE, A. \& PEREIRA, A. K. Política fiscal no Brasil contemporâneo: investimento público e ciclos econômicos. Brasília: Ipea, 2018.

ORAIR, R.. Investimento público no Brasil: trajetória e relações com o regime fiscal. Brasília: Ipea, 2016. (Texto para Discussão, $\mathrm{n}^{\circ}$ 2215).

PINHEIRO, M. S. O papel dos fundos parafiscais no fomento: FGTS e FAT. Brasília: Ipea, 1997. (Texto para Discussão, n. 485).

PROCHNIK, M. Fontes de recursos do BNDES. Revista do BNDES, v. 2, n. 4, p. 1995.

PUGA, F. \& GABRIELLI, H. O BNDES e o investimento: 2000 a 2016. Rio de Janeiro: BNDES, 2018. (Texto para Discussão, n. 122). REZENDE, F. \& AZEREDO, B. Fundos sociais. Rio de Janeiro: Ipea, 1986. (Texto para Discussão, n. 85).

RODRIGUES, D. A.; AFONSO, J. R.; PAIVA, S. M. Instituições financeiras de desenvolvimento: revisitando lições das experiências internacionais. Revista do BNDES, n.48, 2017.

ROUTLEY, L. Developmental states: a review of the literature. Manchester, ESID Working Paper n. 03, 2012.

SANTOS, V. M. Por dentro do FAT. Revista do BNDES, v. 13, n. 26, pp. 3-14, 2006. 
SCHETTINI, B. P. et al. Resultado estrutural e impulse fiscal. In: IPEA. Finanças públicas e macroeconomia no Brasil, v. 1. Brasília: IPEA, 2014. (v.1)

SILVA, Sandro P. Financiamento das políticas públicas de trabalho e renda no Brasil: uma análise a partir da trajetória operacional do Fundo de Amparo ao Trabalhador (FAT). Brasília: Ipea, 2018a. (Texto para Discussão, n. 2437).

IPEA. Propostas de reformulação no arranjo de financiamento e da agenda programática do sistema público de emprego, trabalho e renda no Brasil. Mercado de Trabalho: conjuntura e análise. Brasília: Ipea, 2018b. n. 65. IPEA. A dimensão político-relacional das políticas de mercado de trabalho no Brasil: a agenda deliberativa do Codefat. Brasília: Ipea, 2019a. (Texto para Discussão, n. 2503).
IPEA. O paradigma de sistema público de emprego da OIT e sua construção histórica no Brasil. Brasília: Ipea, 2020. (Texto para Discussão, n. 2562).

SILVA, Napoleão L.; SACCARO, Alice. Efeitos do BNDES nas firmas brasileiras: um estudo de análise de sobrevivência para os anos de 2002 a 2016. $47^{\circ}$ Encontro Nacional de Economia, Anais..., São Paulo, Anpec, 2019.

TINOCO, G.; BORÇA Jr, G. \& MACEDO, H. Fundo de Amparo ao Trabalhador (FAT): breve histórico, condições atuais e perspectivas. Revista do BNDES, v. 25, n.50, pp.139202, 2018.

WADE, R. El mercado dirigido: la teoría económica e la function del gobierno en la industrialización del Este de Asia. México: Fondo de Cultura Económica, 1999.

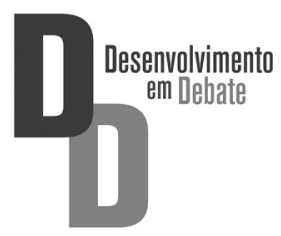




\begin{tabular}{|c|c|c|c|c|c|c|c|c|c|c|c|c|c|c|}
\hline$\frac{a}{\delta}$ & \begin{tabular}{l}
$\hat{n}$ \\
\multirow{+}{*}{} \\
$\stackrel{0}{+}$
\end{tabular} & 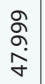 & $\stackrel{\llcorner}{m}$ & $\underset{\mathscr{\gamma}}{\tilde{y}}$ & $\begin{array}{l}\bar{n} \\
\infty \\
\infty \\
\infty\end{array}$ & 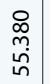 & $\underset{\substack{\stackrel{\infty}{m} \\
\stackrel{m}{m}}}{ }$ & 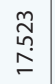 & $m$ & $\stackrel{\infty}{m}$ & 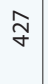 & 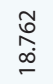 & $\frac{8}{\frac{0}{6}}$ & $\begin{array}{l}\stackrel{+}{\tilde{\omega}} \\
\hat{T}\end{array}$ \\
\hline$\stackrel{\infty}{\infty}$ & $\begin{array}{c}\stackrel{m}{m} \\
\stackrel{\infty}{\infty}\end{array}$ & $\begin{array}{c}\hat{n} \\
\stackrel{\sigma}{f}\end{array}$ & 寸 & $\Sigma$ & $\begin{array}{l}\text { ષ્ } \\
\stackrel{2}{\sigma} \\
\stackrel{\sigma}{\circ}\end{array}$ & $\begin{array}{l}\text { ¿े } \\
\text { in } \\
\text { ம் }\end{array}$ & 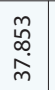 & $\begin{array}{l}\infty \\
\infty \\
\infty \\
\infty \\
\stackrel{0}{0}\end{array}$ & $\infty$ & $\stackrel{f}{f}$ & $\frac{n}{i n}$ & 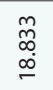 & 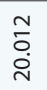 & 웜 \\
\hline $\bar{i}$ & $\begin{array}{l}\text { ro } \\
\stackrel{+}{+} \\
\text { gn }\end{array}$ & 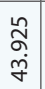 & 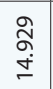 & g & $\begin{array}{l}\stackrel{\sim}{\tilde{\sigma}} \\
\stackrel{\sigma}{\sigma}\end{array}$ & $\begin{array}{l}\tilde{y} \\
\text { mેa } \\
\text { nิ }\end{array}$ & $\frac{\tilde{m}}{\stackrel{+}{\sigma}}$ & 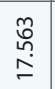 & $\tilde{0}$ & $\hat{m}$ & 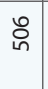 & $\begin{array}{l}\stackrel{8}{\circ} \\
\stackrel{-}{=}\end{array}$ & 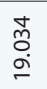 & 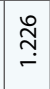 \\
\hline$\stackrel{0}{\circ}$ & 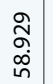 & 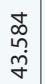 & $\begin{array}{l}\text { Uू } \\
\dot{0} \\
\dot{+}\end{array}$ & 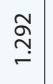 & $\begin{array}{l}m \\
\stackrel{0}{0} \\
\grave{N}\end{array}$ & $\frac{m}{\frac{m}{n}}$ & $\begin{array}{l}\overline{\tilde{r}} \\
\stackrel{\gamma}{\forall}\end{array}$ & 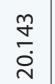 & 0 & ถn & 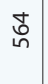 & 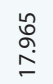 & 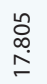 & $\widehat{\widehat{\vartheta}}$ \\
\hline$\stackrel{n}{\infty}$ & 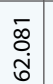 & $\begin{array}{c}\stackrel{\infty}{\underset{丶}{c}} \\
\stackrel{\dot{m}}{n}\end{array}$ & $\begin{array}{c}0 \\
\stackrel{2}{0} \\
\infty\end{array}$ & 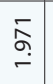 & $\begin{array}{l}\text { 芒 } \\
\stackrel{ }{ }\end{array}$ & $\begin{array}{l}\underset{1}{~} \\
\stackrel{g}{n}\end{array}$ & $\begin{array}{l}\bar{i} \\
\text { oj }\end{array}$ & 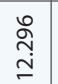 & 0 & $\mathscr{\infty}_{\infty}$ & $\underset{\text { Nె}}{\text { ñ }}$ & 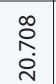 & 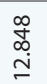 & ڤิ ڤิ \\
\hline$\stackrel{\nabla}{\sim}$ & $\begin{array}{l}\text { ু̊ } \\
\text { ஸे }\end{array}$ & $\begin{array}{l}\hat{D} \\
\text { ֻ. } \\
\text { in }\end{array}$ & $\begin{array}{l}\bar{\infty} \\
\infty \\
\infty \\
\infty\end{array}$ & & $\begin{array}{l}m \\
\infty \\
\overbrace{n} \\
\emptyset\end{array}$ & $\begin{array}{l}m \\
\infty \\
m \\
o \infty \\
o\end{array}$ & $\begin{array}{l}\stackrel{0}{\circ} \\
\swarrow \\
\dot{\sigma}\end{array}$ & 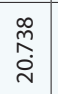 & - & $\bar{\infty}$ & àg & $\begin{array}{l}\stackrel{+}{\infty} \\
\stackrel{\text { స }}{\text { ते }}\end{array}$ & $\begin{array}{l}\stackrel{n}{N} \\
\stackrel{n}{r}\end{array}$ & $\underset{\nearrow}{\check{C}}$ \\
\hline$\stackrel{m}{\bar{n}}$ & $\begin{array}{c}\stackrel{m}{m} \\
\infty \\
\tilde{n} \\
\dot{0}\end{array}$ & $\begin{array}{l}\text { ते } \\
\text { ڤn } \\
\text { ผn }\end{array}$ & 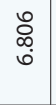 & $\begin{array}{l}\hat{ก} \\
\stackrel{-}{-}\end{array}$ & $\begin{array}{l}\hat{\imath} \\
\stackrel{\sigma}{=}\end{array}$ & 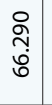 & $\begin{array}{l}\stackrel{9}{0} \\
\text { g }\end{array}$ & $\begin{array}{l}\text { 을 } \\
\text { ○ें } \\
\text { N }\end{array}$ & $a$ & $\stackrel{n}{0}$ & $\underset{\sim}{\sim}$ & $\begin{array}{l}\bar{\infty} \\
\stackrel{\infty}{\sim} \\
\underset{\sim}{N}\end{array}$ & $\begin{array}{l}\stackrel{\infty}{\infty} \\
\stackrel{m}{+} \\
\stackrel{+}{-}\end{array}$ & $\begin{array}{l}\text { ¿े } \\
\stackrel{0}{+} \\
+\end{array}$ \\
\hline$\underset{N}{\sim}$ & $\begin{array}{l}\stackrel{n}{N} \\
\hat{\emptyset}\end{array}$ & $\underset{\substack{\text { m } \\
\text { în }}}{ }$ & $\stackrel{\infty}{\infty}$ & $\begin{array}{l}\hat{n} \\
\stackrel{m}{r}\end{array}$ & $\begin{array}{l}\stackrel{n}{ } \\
\infty \\
\grave{\sim}\end{array}$ & $\begin{array}{l}\frac{n}{m} \\
\frac{m}{\sigma}\end{array}$ & $\frac{\frac{a}{\infty}}{\frac{\sigma}{\sigma}}$ & $\begin{array}{l}\infty \\
\infty \\
0 \\
\infty \\
\stackrel{0}{0}\end{array}$ & $\infty$ & $\stackrel{\nabla}{\sim}$ & రి & $\begin{array}{l}\text { ôे } \\
\stackrel{\infty}{\text { N }} \\
\text { N }\end{array}$ & 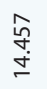 & 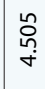 \\
\hline $\bar{i}$ & 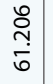 & $\begin{array}{l}\hat{\hat{o}} \\
\stackrel{i}{n}\end{array}$ & $\underset{J}{ \pm}$ & $\begin{array}{l}\stackrel{+}{\infty} \\
\stackrel{m}{-}\end{array}$ & $\begin{array}{l}\infty \\
\underset{6}{0} \\
\infty \\
\stackrel{0}{0}\end{array}$ & $\begin{array}{l}\stackrel{0}{0} \\
\stackrel{0}{0} \\
\stackrel{\circ}{n}\end{array}$ & $\begin{array}{l}\stackrel{\circ}{ } \\
\infty \\
\infty \\
m\end{array}$ & $\begin{array}{l}\hat{ᄋ} \\
o \\
\wp\end{array}$ & $\stackrel{\mathscr{n}}{\simeq}$ & $\stackrel{\text { ㅇ }}{\sim}$ & $\hat{\vartheta}$ & 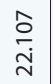 & $\begin{array}{l}\stackrel{2}{ } \\
\hat{n} \\
\end{array}$ & $\hat{n}$ \\
\hline 음 & $\begin{array}{l}m \\
\infty \\
m \\
\dot{\forall} \\
\end{array}$ & $\begin{array}{l}\stackrel{+}{m} \\
o \\
\stackrel{\circ}{0}\end{array}$ & $\stackrel{m}{\stackrel{m}{r}}$ & $\stackrel{0}{\stackrel{n}{n}}$ & $\begin{array}{l}m \\
\infty \\
0 \\
\infty \\
\infty\end{array}$ & 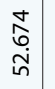 & $\begin{array}{l}\text { ণ } \\
\text { ஸे } \\
\text { లn }\end{array}$ & $\begin{array}{l}\infty \\
\stackrel{\circ}{h} \\
\end{array}$ & $\stackrel{\mathscr{W}}{\sim}$ & $\stackrel{\Xi}{\simeq}$ & $\underset{\infty}{\infty}$ & $\begin{array}{l}\frac{n}{n} \\
\stackrel{n}{N} \\
\end{array}$ & 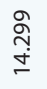 & 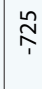 \\
\hline ஓे & $\begin{array}{l}\varrho \\
\infty \\
\infty \\
\stackrel{f}{f}\end{array}$ & $\begin{array}{l}\infty \\
\stackrel{\infty}{\wedge} \\
\dot{f}\end{array}$ & f & $\underset{\bullet}{\stackrel{-}{2}}$ & $\begin{array}{l}\bar{o} \\
\stackrel{\rho}{\sigma} \\
\stackrel{\sigma}{2}\end{array}$ & $\begin{array}{l}\stackrel{n}{n} \\
\\
\end{array}$ & 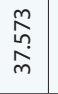 & $\begin{array}{l}\stackrel{n}{N} \\
\stackrel{+}{ \pm}\end{array}$ & ঠి & $\stackrel{9}{\Sigma}$ & $\underset{0}{\square}$ & $\begin{array}{l}\bar{\infty} \\
\stackrel{\infty}{+} \\
\infty \\
\infty\end{array}$ & $\frac{\stackrel{n}{\sigma}}{=}$ & $\begin{array}{l}\text { ᄋ } \\
\text { + }\end{array}$ \\
\hline$\stackrel{\text { : }}{\circ}$ & $\begin{array}{l}\hat{n} \\
\text { in } \\
\text { n. }\end{array}$ & $\begin{array}{l}8 \\
0 \\
i \\
\text { in }\end{array}$ & in & 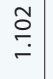 & 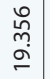 & $\begin{array}{l}\stackrel{n}{\frac{n}{7}} \\
\dot{J}\end{array}$ & 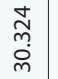 & 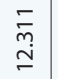 & $\underset{\sim}{\sim}$ & : & ু & $\begin{array}{l}\text { mo } \\
\text { } \\
\text { o. }\end{array}$ & 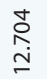 & $\underset{\infty}{\stackrel{n}{\infty}}$ \\
\hline ঠे & $\begin{array}{l}\stackrel{\Re}{N} \\
\dot{J}\end{array}$ & $\begin{array}{l}\tilde{m} \\
\stackrel{m}{\tilde{F}} \\
\tilde{F}\end{array}$ & $\stackrel{m}{\longrightarrow}$ & $\begin{array}{l}\stackrel{+}{O} \\
-\end{array}$ & 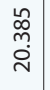 & 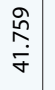 & $\begin{array}{l}\underset{\sim}{\infty} \\
\infty \\
\infty \\
\underset{\sim}{\infty}\end{array}$ & $\underset{\stackrel{్}{\leftarrow}}{\leftarrow}$ & $\stackrel{\infty}{\sim}$ & $\stackrel{\infty}{\stackrel{\sim}{~}}$ & $\underset{\stackrel{\sim}{\sim}}{\check{C}}$ & $\begin{array}{l}\hat{n} \\
\hat{n} \\
\infty \\
\infty\end{array}$ & 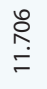 & $\begin{array}{l}\text { Oे } \\
\infty \\
+\end{array}$ \\
\hline 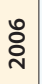 & $\begin{array}{l}\bar{f} \\
\dot{f} \\
\dot{f}\end{array}$ & $\begin{array}{l}\hat{O} \\
\infty \\
\dot{\sigma} \\
\dot{f}\end{array}$ & $\bullet$ & $\stackrel{\infty}{\circ}$ & $\begin{array}{l}\stackrel{\infty}{\underset{N}{N}} \\
\grave{N}\end{array}$ & $\begin{array}{l}\stackrel{8}{\infty} \\
\overleftarrow{m} \\
m\end{array}$ & $\frac{\stackrel{\infty}{\sim}}{\underset{D}{\sim}}$ & $\begin{array}{l}\text { \& } \\
\text { o. }\end{array}$ & $\stackrel{n}{\simeq}$ & $\frac{m}{\sim}$ & 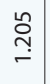 & 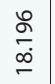 & $\begin{array}{l}\stackrel{\text { సે }}{=} \\
=\end{array}$ & $\underset{\stackrel{m}{m}}{\stackrel{m}{n}}$ \\
\hline 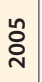 & $\begin{array}{l}\stackrel{m}{a} \\
\dot{f}\end{array}$ & 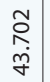 & ถn & $\stackrel{0}{0}$ & $\begin{array}{l}\stackrel{n}{\aleph} \\
\stackrel{n}{\sim} \\
\sim\end{array}$ & $\begin{array}{l}\text { Oे } \\
m \\
\stackrel{m}{\text { m }}\end{array}$ & $\begin{array}{l}\stackrel{\mathbb{0}}{\circ} \\
\stackrel{+}{\sim}\end{array}$ & స̃. & $\stackrel{\bullet}{\sim}$ & $\stackrel{n}{\sim}$ & ถู & 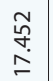 & $\begin{array}{l}\stackrel{\circ}{1} \\
\infty \\
\stackrel{0}{0} \\
\stackrel{0}{0}\end{array}$ & $\frac{m}{i}$ \\
\hline 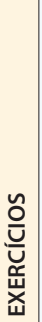 & 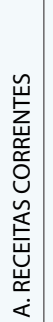 & 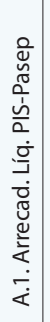 & 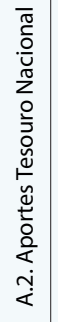 & 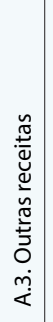 & 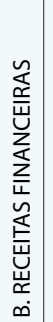 & 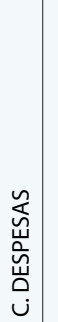 & 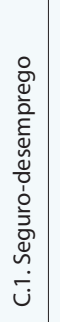 & 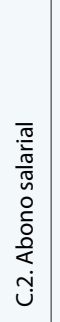 & 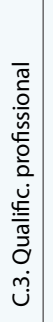 & 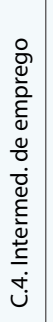 & 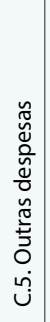 & 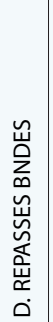 & 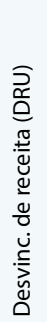 & 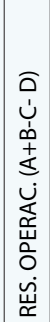 \\
\hline
\end{tabular}

